\title{
CARACTERIZAÇÃO FÍSICA, QUÍMICA E MINERALÓGICA DE UMA AMOSTRA DE MINÉRIO DE FERRO DE BRUCUTU
}

\author{
Geriane Macedo Rocha' \\ Gizele Maria Campos Gonçalves ' \\ Kennedy da Silva Ramos ' \\ Tiany Guedes Cota ' \\ Rosa Malena Fernandes Lima '
}

\section{Resumo}

A caracterização de um minério permite a previsibilidade do seu comportamento frente aos processos de concentração. Apenas dados granuloquímicos nem sempre são suficientes, sendo o reconhecimento das espécies minerais, suas proporções, forma de grãos e liberabilidade também fundamentais. Neste trabalho é apresentada a caracterização física, química e mineralógica de um minério de ferro da mina de Brucutu/Quadrilátero Ferrífero-MG. Foram realizadas análises granulométricas por peneiramento e granulômetro a laser, químicas por fluorescência de raios $\mathrm{X}$ e mineralógica por microscopia óptica e difração de raios $\mathrm{X}$. Baseado nos resultados obtidos, o minério foi classificado como friável, com teor global de Fe igual a $42,9 \%$ e $\mathrm{SiO}_{2}$ de $36,1 \%$. Os minerais de ferro identificados foram hematita e goethita e, o principal mineral de ganga o quartzo. $\mathrm{Na}$ fração $+\mathrm{I}, 0 \mathrm{~mm}$ o quartzo ocorre majoritariamente em partículas mistas com os grãos de hematita e goethita. Abaixo desta granulometria, o mesmo ocorre como partículas livres. Acima de $0,15 \mathrm{~mm}$ a hematita é predominantemente porosa, e abaixo de 0,15 mm granular. A goethita encontra-se associada à hematita granular em todas as frações granulométricas.

Palavras-chave: Caracterização; Minério de ferro; Beneficiamento mineral.

\section{PHYSICAL, CHEMICAL AND MINERALOGICAL CHARACTERIZATION OF A BRUCUTU IRON ORE SAMPLE}

\begin{abstract}
The characterization of an ore allows the predictability of its behavior in relation to the concentration methods. Only size and chemical analyses are not always sufficient, and the recognition of mineral species, their proportions, grain form, and liberability are also fundamental. In this work the physical, chemical and mineralogical characteristics of an iron ore from Brucutu mine in Quadrilátero Ferrífero is presented. Particle size analyses were carried out by sieve and laser granulometer, chemistry by $\mathrm{X}$-ray fluorescence and mineralogical by optical microscopy and X-ray diffraction. Based on the results obtained, the ore was classified as friable, with an overall $\mathrm{Fe}$ content of $42.9 \%$ and $\mathrm{SiO}_{2}$ of $36.1 \%$. The iron minerals identified were hematite and goethite, and the main gangue mineral was quartz. In the fraction $+1.0 \mathrm{~mm}$ the quartz occurs mainly in mixed particles with the hematite and goethite grains. Below this size, the same occurs as free particles. Above $0.15 \mathrm{~mm}$ the hematite is predominantly porous, and below $0.15 \mathrm{~mm}$ granular. Goethite is associated with granular hematite in all size distribution. Keywords: Characterization; Iron ore; Mineral processing.
\end{abstract}

\section{INTRODUÇÃO}

O sucesso no beneficiamento de minérios requer como princípio o real conhecimento de suas propriedades físicas e químicas para entender qual o produto a ser esperado frente a cada etapa do processo. Segundo Luz e Lins [I], as principais técnicas de concentração atualmente aplicadas são sensíveis a pequenas alterações nestas propriedades físico-quimicas. Diante disto e, considerando a complexidade crescente dos minérios, dados granuloquímicos não são muitas das vezes suficientes para descrever seu comportamento. O entendimento e reconhecimento das espécies minerais bem

'Programa de Pós-graduação em Engenharia Mineral, Departamento de Engenharia de Minas, Universidade Federal de Ouro Preto - UFOP, Ouro Preto, MG, Brasil. E-mail: rosa@demin.ufop.br

2176-1523 (C) 2019 Associação Brasileira de Metalurgia, Materiais e Mineração. Publicado pela ABM. Este é um artigo de acesso aberto distribuído sob os termos da licença Creative Commons CC BY-NC-ND (Attribution-NonCommercial-NoDerivs) - https:// creativecommons.org/licenses/by-nc-nd/4.0\%. 
como suas proporções, forma de grãos e grau de liberação são fundamentais para compreensão da performance do minério dentro de uma planta de concentração [2].

O Quadrilátero Ferrífero/MG é uma importante província mineral, principalmente de minérios de ferro, que segundo dados do sumário mineral possuem teor médio de $46,3 \%$ de Fe e representam 72,5\% das reservas totais do país [3]. De acordo com Rosière e Chemale [4], as formações ferríferas dessa região apresentam características mineralógicas e texturais distintas, a depender do processo de metamorfismo e deformação as quais foram submetidas. Segundo estes autores, as formações ferríferas do Quadrilátero Ferrífero compreendem um sistema mineralógico monótono de hematita, como principal mineral de ferro, e quartzo, como ganga.

Alkmim [5] classifica as principais litologias hospedeiras de mineralização de ferro do Quadrilátero Ferrífero de acordo com suas propriedades químicas e físicas (tenacidade), como: itabiritos goethíticos, friáveis e compactos, itabiritos silicosos, friáveis e compactos, itabiritos compactos e itabiritos manganesíferos. Segundo a pesquisadora, os itabiritos da borda oeste apresentam hematita lamelar euédrica, magnetita com cristais bem formados e quartzo em sua maioria com contatos poligonais. Já os itabiritos da borda leste, apresentam a hematita nas formas especular e lamelar anédrica, martita como a alteração de magnetita para hematita, e quartzo anédrico com contatos serrilhados.

A definição da tipologia dos minérios, obtida em função de suas características granuloquímicas e mineralógicas, é essencial para otimização de reservas e melhores resultados no beneficiamento. Entretanto, muitas vezes, esta definição tipológica é baseada apenas em dados granuloquímicos (friável/compacto, rico/pobre) e petrográficos, o que pode acarretar em uma definição errônea ou não adequada. Rocha [6] caracterizando os itabiritos anfibolíticos classificados como estéril na mina de Alegria-Samarco, observou que estes eram essencialmente goethíticos e a partir dos resultados de recuperação em massa e metalúrgica os classificou potencialmente como minérios.

Donskoi et al. [7] afirma que minérios com composições químicas similares, e composições mineralógicas e texturas diferentes apresentam comportamentos distintos no processamento mineral, principalmente nas etapas onde os parâmetros superficiais são mais relevantes como, por exemplo, nas etapas de flotação e de aglomeração. Meyer et al. [8] avaliando os minérios de ferro do Quadrilátero Ferrífero como alimentação da pelotização demonstraram que os minérios com hematita granular apresentavam alto consumo energético na moagem, e aqueles com a hematita especular apresentavam dificuldade de redução de granulometria, devido ao seu hábito cristalino. Já os minerais porosos, como goethita e martita, apresentavam baixo consumo energético na moagem e aumento da superfície específica, parâmetro este importante para etapa de aglomeração.

O presente trabalho teve como objetivo caracterizar do ponto de vista físico, químico e mineralógico uma amostra de minério de ferro proveniente da Mina de Brucutu, localizada a sudeste do estado de Minas Gerais, no município de São Gonçalo do Rio Abaixo, na borda leste do Quadrilátero Ferrífero, mais especificamente no Sinclinal Gandarela.

\section{MATERIAIS E MÉTODOS}

A amostra (5kg) recebida no Laboratório de Tratamento de Minérios do DEMIN/UFOP foi homogeneizada e quarteada para retirada de alíquotas para os ensaios de caracterização.

As características físicas avaliadas foram: umidade, distribuição granulométrica e densidade. A umidade foi determinada através da medida da massa do material antes e após a secagem, em estufa com temperatura controlada em $105^{\circ} \mathrm{C}$, até que não houvesse variação da mesma. Para a distribuição granulométrica adotou-se o peneiramento combinado em duplicata, utilizando o peneirador vibratório suspenso pelo tempo de 20 minutos. A fração $-0,075 \mathrm{~mm}$ foi analisada via granulômetro a laser-CILAS I064. Para determinação do peso específico utilizou-se o picnômetro a hélio, modelo Ultrapyc I200e do Laboratório de Propriedades Interfaciais do DEMIN/UFOP. Para essas análises foi utilizado porta amostra de tamanho médio, pressão alvo igual a $19 \mathrm{psi}$, tempo de purga igual a 4 minutos e número de varreduras igual a 3 . A densidade foi determinada pela média entre os três valores obtidos nas três medições, com desvio padrão de $0,005 \%$.

Foram efetuadas análises químicas e mineralógicas das frações granulométricas $+I, 0 \mathrm{~mm},-1,0+0,15 \mathrm{~mm}$ e $-0,15 \mathrm{~mm}$, conforme análises de rotina adotada pela Mina de Brucutu.

A composição química da amostra global e das frações granulométricas foi determinada por fluorescência de raios $X(F R X)$ com dispersão por comprimento de onda (WDXFR) no Laboratório Químico de Brucutu. Para tal foram confeccionadas pastilhas prensadas das amostras. Para determinação do $\mathrm{FeO}$ foi utilizado a análise química por via úmida, aplicando o método do cloreto de titânio III [9]. A determinação da perda por calcinação (PPC) da amostra global e das frações granulométricas foi realizada utilizando forno mufla a uma temperatura de $1000{ }^{\circ} \mathrm{C}$ por I hora.

A análise termogravimétrica (TGA) da amostra global foi efetuada pelo equipamento TAQ50 (TA Instruments) do Laboratório de Espectroscopia Infravermelha/Análise Termogravimétrica do DEMIN. O gás utilizado foi o nitrogênio com vazão de $100 \mathrm{~mL} / \mathrm{min}$, sendo as amostras aquecidas a partir de temperatura ambiente até $1000^{\circ} \mathrm{C}$, com rampa de aquecimento de $10^{\circ} \mathrm{C} / \mathrm{min}$.

A caracterização mineralógica da amostra global foi realizada por meio de análise macroscópica, a olho nu, e difração de raios $X$ usando o difratômetro D2 Phases - Bruker, pertencente ao DEMET/UFOP, com radiação proveniente de um anodo de cobre e varredura realizada de $2^{\circ}$ a $80^{\circ}$ (ângulo 20). As seções polidas das faixas granulométricas supracitadas foram analisadas, usando luz refletida no microscópio ótico Leica DMLP do Laboratório de Microscopia ótica do DEMIN. 


\section{RESULTADOS E DISCUSSÃO}

Observa-se que o $d_{80}$ e $\circ d_{50}$ da amostra estudada é de $\mathrm{I}, \mathrm{I} 8$ e $0, \mathrm{I}, 48 \mathrm{~mm}$, respectivamente (Figura I). De acordo com o critério de classificação adotado para Brucutu esse minério pode ser considerado friável já que o passante em $1,0 \mathrm{~mm}$ é maior que $80 \%$ [I0]. Amorim e Alkmim [ I I] estudando os minérios de ferro da região leste do Quadrilátero Ferrífero assumem como friáveis aqueles em que o percentual passante em $6,3 \mathrm{~mm}$ fosse maior que $70 \%$. Neste sentido, o resultado de $93 \%$ passante em $6,3 \mathrm{~mm}$ confirma a classificação deste material como friável.

A umidade natural do minério foi $4,39 \%$ e o peso específico foi $3,86 \mathrm{~g} / \mathrm{cm}^{3}$, que está coerente com os valores de peso específico de minérios de ferro do Quadrilátero Ferrífero, determinados por Lima et al. [12], que encontraram valores entre 3,4 e $4,0 \mathrm{~g} / \mathrm{cm}^{3}$.

A Tabela I apresenta os resultados da análise granuloquímica. $\mathrm{O}$ teor de $\mathrm{Fe}$ global obtido foi de $42,9 \%$, sendo a amostra classificada como itabirito pobre $(<45 \% \mathrm{Fe})$, conforme Carvalho [13]. Devido ao cenário de exaustão das reservas de alto conteúdo metálico, o aproveitamento de itabiritos com teores similares ao minério estudado e, até mais baixos, já vem ocorrendo em várias unidades industriais. Os estudos de Lima et al. [12] mostraram que foi possível a obtenção de concentrados com especificação de standard sínter feed a partir de minérios classificados como pobres, com teores variando de $31,5 \%$ a $40,1 \%$ de $\mathrm{Fe}$.

A fração granulométrica $+1,0 \mathrm{~mm}$ possui maior teor de $\mathrm{Fe}(\sim 59,7 \%)$, que representa $26,8 \%$ do ferro contido na amostra. Nesta fração o PPC é mais alto, que pode estar relacionado à presença de minerais hidratados (goethita $\mathrm{e}$ caulinita). A fração granulométrica $-1,0+0,15 \mathrm{~mm}$ possui menor percentual de PPC, o que sugere menor participação de minerais hidratados. Em relação aos contaminantes $\left(\mathrm{Al}_{2} \mathrm{O}_{3}, \mathrm{Mn}\right.$ e P), observa-se que apesar de não serem significativamente altos, apresentam-se em maior proporção na fração $-0,15 \mathrm{~mm}$, podendo indicar presença de argilominerais. Analisando a distribuição dos constituintes majoritários $\left(\mathrm{Fe} \mathrm{e} \mathrm{SiO}_{2}\right)$, estes são maiores na fração $-0,15 \mathrm{~mm}$.

A Figura 2 apresenta o termograma da amostra global. Nota-se que há uma perda de massa de $2,05 \%$ entre as temperaturas de 30 e $1000^{\circ} \mathrm{C}$. No intervalo de 30 a $200^{\circ} \mathrm{C}$ a massa perdida pode estar associada à eliminação de água fisicamente ligada por forças de van der Waals, e à perda de água mantida por ligação de hidrogênio [14]. À temperatura de $200{ }^{\circ} \mathrm{C}$ se inicia uma expressiva perda de massa que se estende até $350^{\circ} \mathrm{C}$, podendo ser relacionada a perda da hidroxila da goethita. Segundo Rocha [6] e Leonel [15] a desidroxilação da goethita ocorre na faixa de $226-425^{\circ} \mathrm{C}$. Rocha [6] também observou que na faixa de 464 a $642{ }^{\circ} \mathrm{C}$ ocorre a desidroxilação de argilominerais, sendo assim, a perda de massa de 400 a $700^{\circ} \mathrm{C}$, que foi pouco expressiva, pode estar relacionada à desidroxilação de argilominerais.

Através dos dados de perda de massa e teores de $\mathrm{Al}_{2} \mathrm{O}_{3}$, foi efetuada uma estimativa através de cálculo estequiométrico da proporção de minerais hidratados, 0 que resultou em $12,08 \%$ de goethita e $1,34 \%$ de caulinita.

A análise petrográfica indicou que a amostra trata-se de um minério friável de coloração amarronzada, o que sugeriu, a princípio, a presença de goethita. Em termos

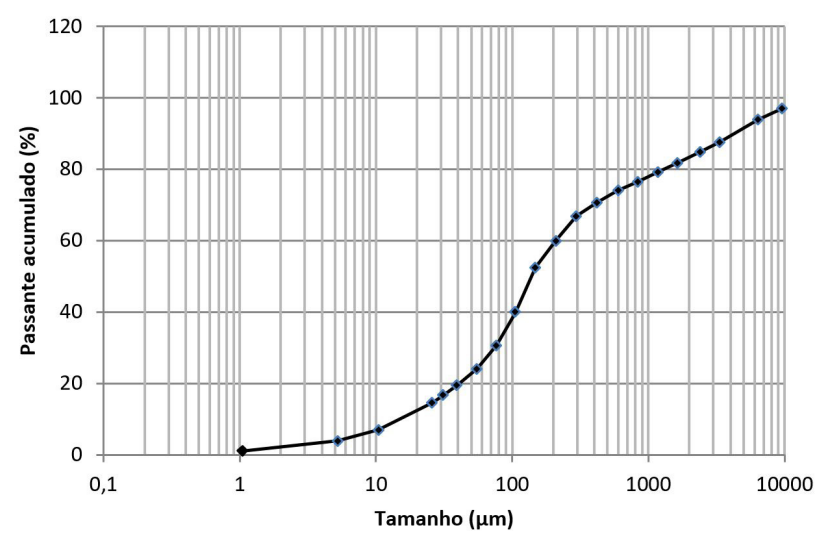

Figura I. Distribuição granulométrica da amostra de minério de ferro estudada.

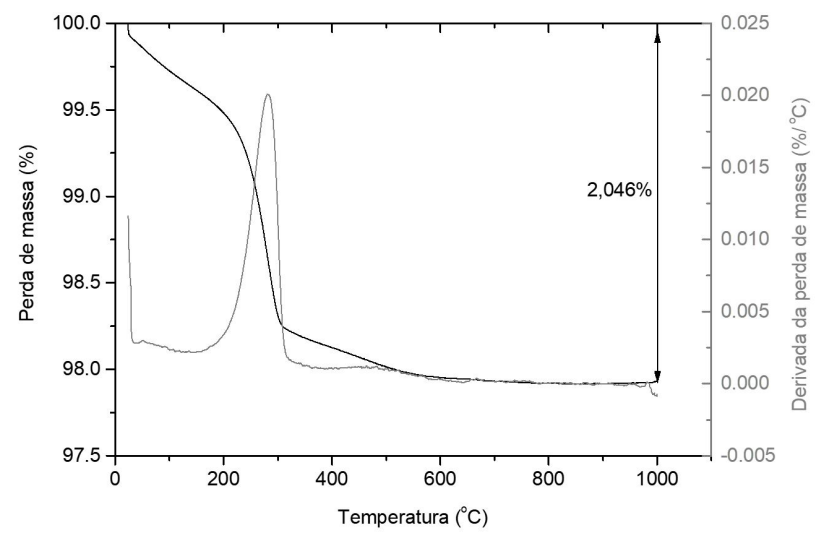

Figura 2. Termograma da amostra de minério de ferro estudada.

Tabela I. Dados da análise química da amostra de minério de ferro estudada

\begin{tabular}{|c|c|c|c|c|c|c|c|c|c|c|c|c|}
\hline \multirow{2}{*}{ Fração $(\mathrm{mm})$} & \multirow{2}{*}{ Peso (\%) } & \multicolumn{9}{|c|}{ Teores (\%) } & \multicolumn{2}{|c|}{ Dist.(\%) } \\
\hline & & $\mathbf{F e}$ & $\mathrm{SiO}_{2}$ & $\mathbf{P}$ & $\mathrm{Al}_{2} \mathrm{O}_{3}$ & Mn & $\mathrm{CaO}$ & MgO & $\mathrm{FeO}$ & PPC & $\mathbf{F e}$ & $\mathrm{SiO}_{2}$ \\
\hline $\mathrm{I}, 0$ & 19,0 & 59,65 & II,73 & 0,058 & 0,45 & 0,073 & 0,001 & 0,01 & 0,15 & 2,63 & 27 & 6 \\
\hline$-1,0+0,15$ & 29,3 & 26,96 & 58,78 & 0,030 & 0,34 & 0,037 & 0,012 & 0,11 & 0,17 & 1,22 & 19 & 47 \\
\hline$-0,15$ & 51,7 & 44,52 & 33,86 & 0,055 & 0,81 & 0,093 & 0,035 & 0,09 & 0,16 & 1,68 & 54 & 47 \\
\hline Global & 100 & 42,89 & 36,03 & 0,050 & 0,59 & 0,080 & 0,004 & 0,02 & 0,16 & 2,14 & 100 & 100 \\
\hline
\end{tabular}


gerais, há presença de fragmentos grossos, onde é comum observar os grãos de quartzo incrustados na hematita. $\mathrm{Na}$ fração abaixo de $1,0 \mathrm{~mm}$ a sílica apresenta-se liberada.

As imagens obtidas pelo microscópio óptico são apresentadas nas Figuras 3 a 5 . Em todas as frações granulométricas analisadas tem-se o quartzo como o principal mineral de ganga e a hematita como principal mineral-minério.

$\mathrm{Na}$ fração $+1,0 \mathrm{~mm}$ (Figura 3) o quartzo se apresenta em grãos subédricos, em grande parte em partículas mistas, incrustado em grãos de hematita e/ou goethita. O processo de jigagem é usualmente aplicado para frações grossas na concentração de minério de ferro, visando à produção de sinter feed [2]. O fato das partículas minerais não estarem liberadas pode levar à ineficiência desse processo de concentração, promovendo teores de sílica elevados no concentrado. A hematita aparece como grãos anédricos, sinuosos e comumente porosa. Apesar de o material, a princípio, ser classificado como goethítico, a presença do mineral goethita foi pouco significativa. Geralmente a goethita ainda incipiente, ocorre associada a resquícios de hematita granular, mostrando ser produto de hidratação desta última.

$\mathrm{Na}$ fração granulométrica $-I, 0 \mathrm{~mm}+0,15 \mathrm{~mm}$ (Figura 4) o quartzo apresenta-se como grãos de formas euédricas a subédricas, menores que os grãos da hematita. A hematita é comumente porosa e subordinadamente tabular. As formas dos grãos em geral são anédricos para as hematitas porosas e euédricos para as tabulares. A presença de goethita é quase irrelevante, e quando essa é encontrada, apresenta-se associada à hematita granular. A caulinita foi identificada como o principal argilomineral, ocorrendo de forma minoritária.

Para esta faixa granulométrica $(-1,0 \mathrm{~mm}+0,15 \mathrm{~mm})$ podem ser aplicados os métodos de concentração gravítica em espiral e concentração magnética de alta e baixa intensidade [16]. Segundo Ribeiro e Ribeiro [17] a concentração magnética de alta intensidade vem sendo amplamente aplicada devido ao desenvolvimento de equipamentos robustos e de alta tecnologia. $O$ baixo percentual de magnetita presente na amostra também é um fator que favorece esse processo, podendo ser o mais indicado em escala industrial e levar a bons resultados. Ressalta-se que apesar desta fração apresentar o maior percentual de sílica, ela encontra-se em sua maior parte liberada.

O quartzo na fração granulométrica $-0,15 \mathrm{~mm}$ (Figura 5) apresenta-se totalmente livre em grãos bem formados, euédricos e maiores que os grãos de hematita. A hematita é predominantemente granular com forma tabular e raramente porosa. A goethita perfaz uma pequena proporção desta fração e quando encontrada está associada às hematitas granulares euédricas.

A flotação catiônica reversa é o principal método de concentração de minério de ferro para granulometria $-0,15 \mathrm{~mm}$. Neste caso, o tamanho do grão de quartzo pode ser um ponto de atenção para boa eficiência desse processo,
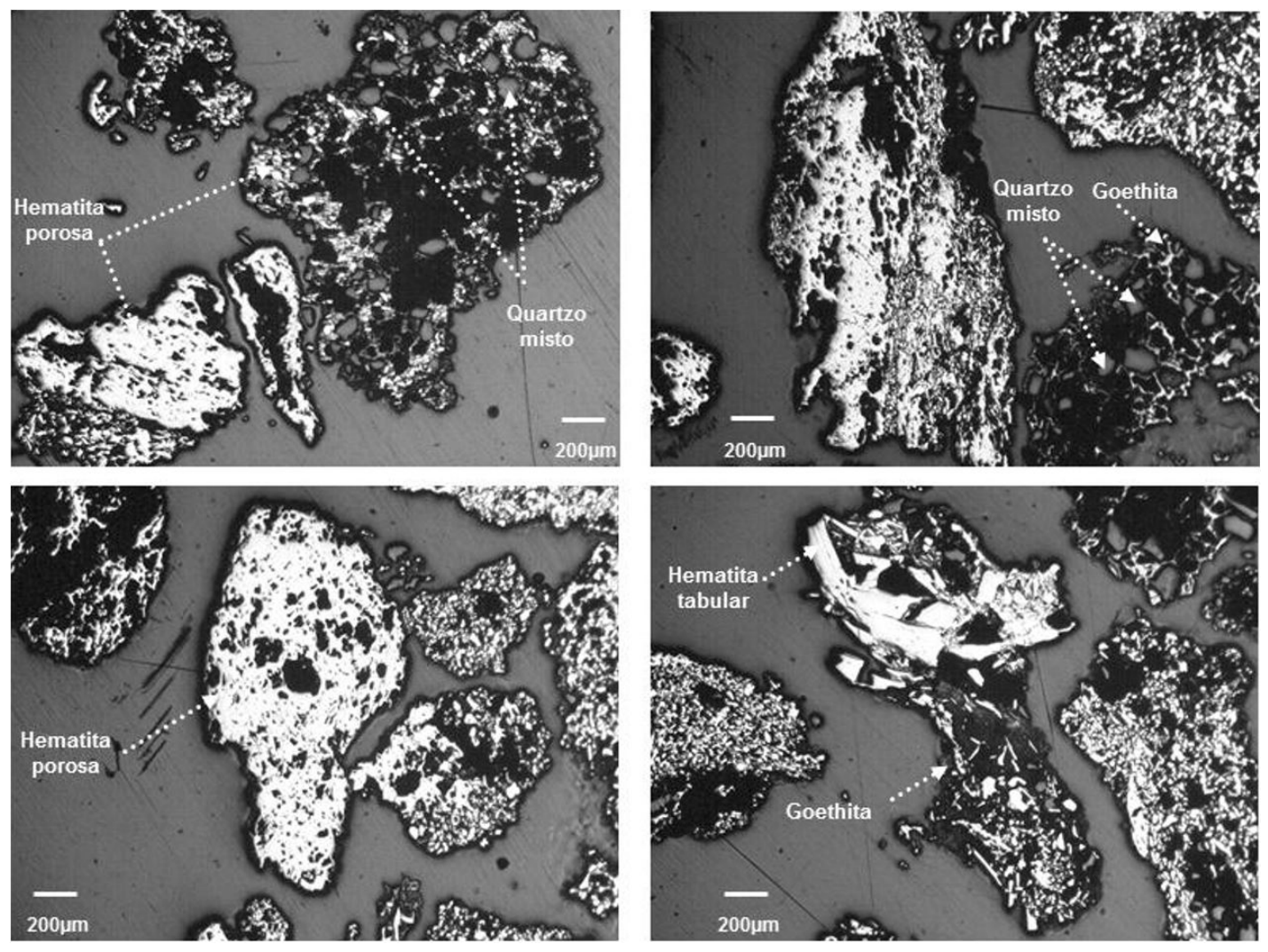

Figura 3. Fotomicrografias em luz natural da fração granulométrica $+I, 0 \mathrm{~mm}$, apresentando partículas mistas constituídas por quartzo e hematita porosa ou quartzo com goethita. 

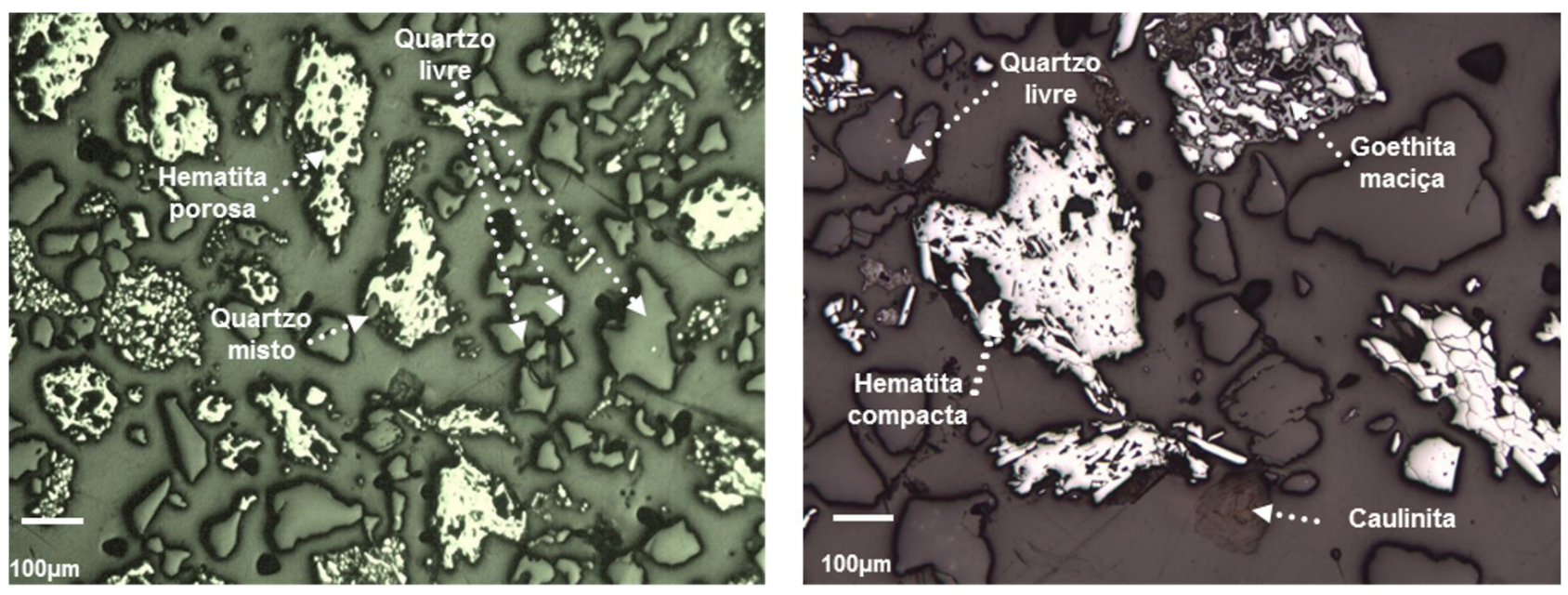

Figura 4. Fotomicrografias em luz natural da fração $-1,0 \mathrm{~mm}+0,15 \mathrm{~mm}$ apresentando hematita porosa (a esquerda), hematita tabular, goethita nas bordas da hematita tabular e caulinita (direita).
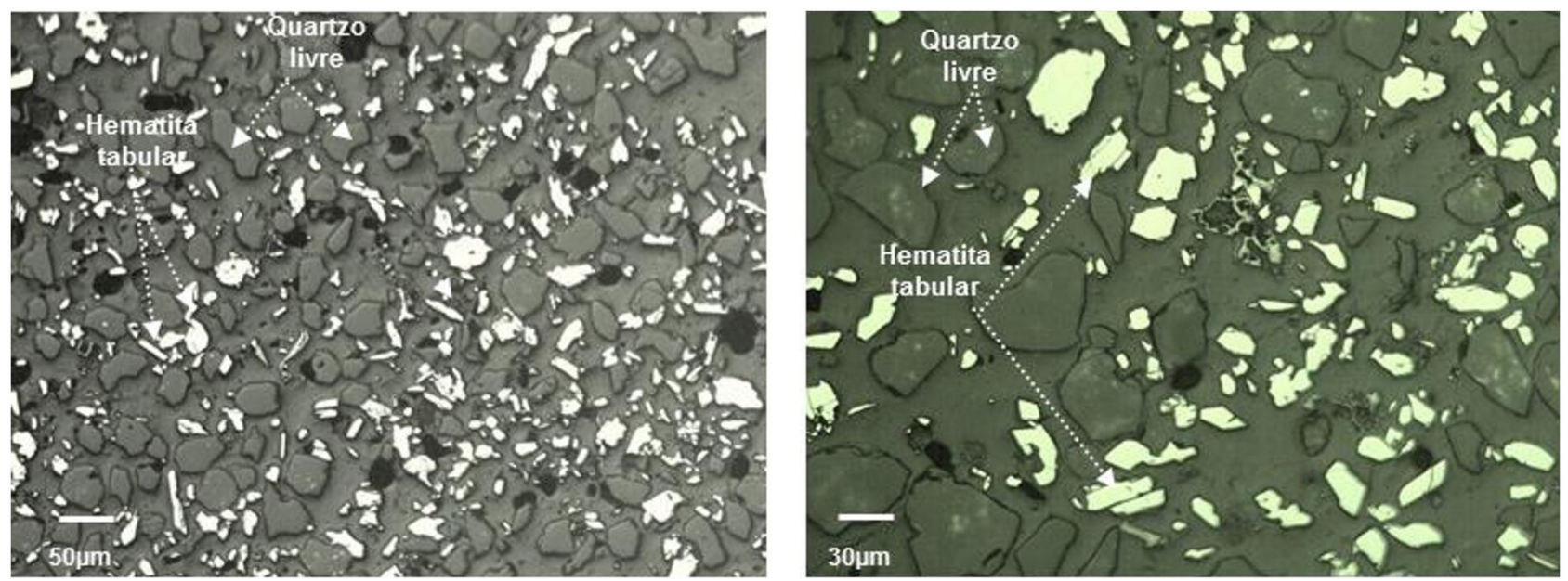

Figura 5. Fotomicrografias em luz natural da fração granulométrica $-0,15 \mathrm{~mm}$, apresentando hematita granular/tabular (a esquerda) com quartzo euédrico livre. À direita hematita tabular e goethita nas bordas da hematita tabular.

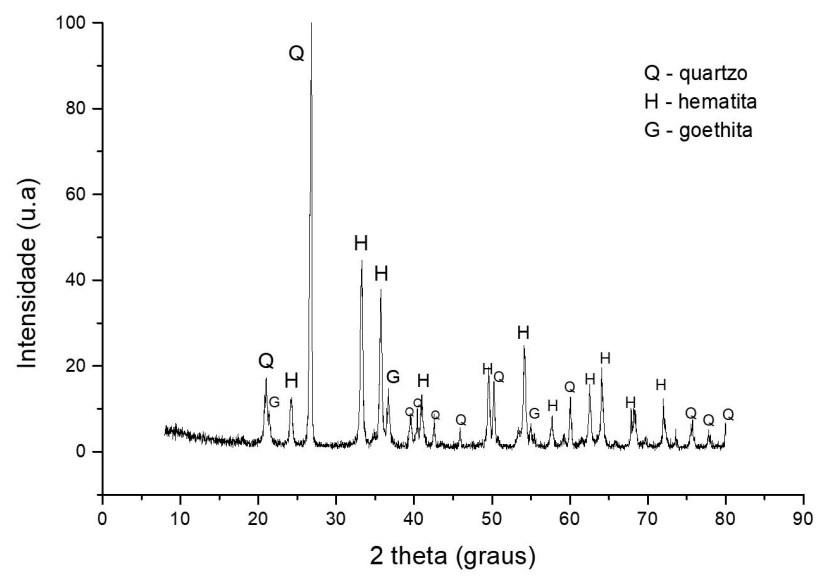

Figura 6. Difratograma de raios $X$ da amostra de minério de ferro estudada. visto que na etapa de transporte pode ocorrer a ruptura do agregado partícula-bolha, devido ao tamanho, ao peso e à insuficiência de cobertura hidrofóbica das superfícies das partículas [18].

As fases cristalinas identificadas no difratograma de raios $X$ da amostra global foram quartzo, hematita e goethita (Figura 6), confirmando a análise da microscopia ótica. A caulinita pode não ter sido identificada por se apresentar em concentração abaixo do limite de detecção dessa técnica.

\section{CONCLUSÕES}

Baseado nos ensaios de caracterização física, química e mineralógica efetuados com a amostra de minério de ferro estudada concluiu-se que: 
i) A amostra apresentou $d_{80}$ de I, $18 \mathrm{~mm}$ e $\circ \mathrm{d}_{50}$ de 0 , $148 \mathrm{~mm}$, sendo classificado como friável. A umidade do minério foi $4,39 \%$ e o peso específico $3,86 \mathrm{~g} / \mathrm{cm}^{3}$, que está coerente com valores de minérios do Quadrilátero Ferrífero;

ii) Os teores recalculados do minério foi $42,9 \%$ de $\mathrm{Fe}$, $36,1 \%$ de $\mathrm{SiO}_{2}, 0,6 \%$ de $\mathrm{Al}_{2} \mathrm{O}_{3}$ e $2,1 \%$ de PPC. A perda total de massa obtida por termogravimetria foi de 2,05\%. Baseado nos teores de $\mathrm{Al}_{2} \mathrm{O}_{3}$ e PPC foi estimado o percentual de $12,1 \%$ de goethita e I,3\% de caulinita na amostra;

iii) Os principais minerais identificados foram o quartzo (mineral de ganga) e a hematita (mineral-minério). Apesar do material ser intitulado na mina como itabirito goethítico, este apresentou baixa proporção de goethita. $\mathrm{Na}$ fração granulométrica $+\mathrm{I}, 0 \mathrm{~mm}$ o quartzo ocorre em partículas mistas com grãos de hematita e goethita, e liberado para frações granulométricas menores $1,0 \mathrm{~mm}$. A hematita apresentou-se predominantemente porosa na fração granulométrica $+0,15 \mathrm{~mm}$, e comumente granular para fração granulométrica - 0, $15 \mathrm{~mm}$. Em todas as frações granulométricas, a goethita estava associada à hematita granular, sugerindo ser produto de hidratação incipiente da mesma.

\section{Agradecimentos}

Os autores agradecem a UFOP, CAPES, CNPq, Fapemig e VALE.

\section{REFERÊNCIAS}

I Luz AB, Lins FF. Introdução ao tratamento de minérios. In: Luz AB, Sampaio JA, França, SCA. Tratamento de minérios. 5. ed. Rio de Janeiro: CETEM/MCP; 2010. p. 3-I5.

2 Araújo AC, Amarante SC, Souza CC, Silva RRR. Ore mineralogy and its relevante for selection of concentration methods in processing of Brazilian iron ores. Mineral Processing and Extractive Metallurgy. 2003; I I 2(I):54-64. http://dx.doi.org/I0.1 I79/037| 955032250I| 439.

3 Brasil. Departamento Nacional de Produção Mineral. Sumário mineral 2015. Brasília: DNPM; 2016. p. 66-67. (vol. 35) [acesso em 31 jan. 20l8]. Disponível em: http://www.anm.gov.br/dnpm/publicacoes/serie-estatisticas-eeconomia-mineral/sumario-mineral/sumario-mineral-brasileiro-20I5

4 Rosière AC, Chemale FJ Jr. Itabiritos e minérios de ferro de alto teor do Quadrilátero Ferrífero: uma visão geral e discussão. Geonomos. 2000;8(2):27-43. http://dx.doi.org/10.18285/geonomos.v8i2. I55.

5 Alkmim AR. Investigação geoquímica e estratigráfica da formação ferrífera Cauê na porção centro-oriental do Quadrilátero Ferrífero [dissertação]. Ouro Preto: Universidade Federal de Ouro; 2014.

6 Rocha JMP. Definição da tipologia e caracterização mineralógica e microestrutural dos itabiritos anfibolíticos das minas de Alegria da Samarco Mineração S.A [tese]. Belo Horizonte: Universidade Federal de Minas Gerais; 2008.

7 Donskoi E, Poliakov A, Holmes R, Suthers S, Ware N, Manuel J, et al. Iron ore textural information is the key for prediction of downstream process performance. Minerals Engineering. 2016;86:10-23. http://dx.doi.org/l0.10 I6/j. mineng.2015.11.009.

8 Meyer M, Casagrande C, Martin LA, Zocatelli T. Influência da participação em maior escala do pellet feed da mina de Brucutu no processo de pelotização Vale-Tubarão. In: Anais do 44 Seminário de Redução de Minério de Ferro e Matérias-primas; $5^{\circ}$ Simpósio Brasileiro de Minério de Ferro; $2^{\circ}$ Simpósio Brasileiro de Aglomeração de Minério de Ferro; 20I4; Belo Horizonte. São Paulo: ABM; 2014 [acesso em 5 fev. 2018]. Disponível em: https://www. researchgate.net/publication/272795890

9 Associação Brasileira de Normas Técnicas - ABNT. NBR 9507: minérios de ferro: determinação do teor de ferro total: método de redução por cloreto de titânio (III). Rio de Janeiro: ABNT; 2003.

10 Vale. Revisão dos recursos da Mina de Brucutu: relatório interno. Belo Horizonte: Vale; 20 I I. 58 p.

I I Amorim LQ, Alkmim FF. New ore types from Cauê Banded Iron Formation Quadrilátero Ferrífero, Minas Gerais, Brazil: responses to the growing demand. In: Proceedings of the Iron Ores Conference; 20I I; Perth. Australia: AusIMM; 20I I. p. 59-7I.

I 2 Lima RMF, Lopes GM, Gontijo CF. Aspectos mineralógicos, físicos e químicos na flotação catiônica inversa de minérios de ferro de baixos teores, do Quadrilátero Ferrífero-MG. Tecnologica em Metalurgia, Materiais e Mineração. 201 I;8(2): I 26-I3 I. http://dx.doi.org/ I0.4322/tmm.20 I I.020.

13 Carvalho BCL. Aproveitamento de minérios de ferro de baixo teor: tendências, tecnologias utilizadas e influências no sequenciamento de lavra [dissertação]. Ouro Preto: Universidade Federal de Ouro Preto; 2012. 
Rocha et al.

I4 Silva MSS. Sinterização em escala de bancada de minério de ferro goethítico calcinado [dissertação]. Ouro Preto: Universidade Federal de Ouro Preto; 2014.

15 Leonel CML. Estudo de Processo de Calcinação como Operação Unitária Adicional na Pelotização de Minérios de Ferro com Altos Valores de PPC [tese]. Belo Horizonte: Universidade Federal de Minas Gerais; 201 I.

16 Wills B. Mineral processing technology. Amsterdam: Amsterdam Press; 1992.

17 Ribeiro JP, Ribeiro CHT. GX-3600: world's largest magnetic separator - up to 800 tph. Revista da Escola de Minas. 2010;63(4):69I-694. http://dx.doi.org/I0.I590/S0370-446720100004000I5.

I8 Rao SR. Surface chemistry of froth flotation: reagents and mechanisms. New York: Springer; 2004. p. 675-703. (vol. 2).

Recebido em: 8 Mar. 2018

Aceito em: 25 Maio 2018 